\title{
IDENTIFICATION AND CONTROL OF AN ASYNCHRONOUS MACHINE USING NEURAL NETWORKS
}

Soumis le 13/03/1999 - Accepté le 25/03/2000

\begin{abstract}
In this work, we present the application of artificial neural networks to the identification and control of the asynchronous motor, which is a complex nonlinear system with variable internal dynamics. We show that neural networks can be applied to control the stator currents of the induction motor. The results of the different simulations are presented to evaluate the performance of the neural controller proposed.
\end{abstract}

Key words: Neural networks, nonlinear control systems, system identification, neuromorphic control, asynchronous machine.

\section{Résumé}

Ce travail présente l'applications des réseaux de neurones artificiels à l'identification et au contrôle du moteur asynchrone, un système non linéaire complexe et aux dynamiques internes variables. Nous avons montré que les réseaux de neurones peuvent être utilisés pour la commande des courants statoriques du moteur à induction. Les résultats de différentes simulations sont présentés pour évaluer la performance du contrôleur neuronal proposé.

Mots clés: Réseaux de neurones, contrôle des systèmes non linéaires, identification des systèmes, contrôle neuromorphique, machine asynchrone.

\section{A. ZERGAOUI \\ A. BENNIA}

Département d'Electronique

Faculté des Sciences de l'Ingénieur

Université Mentouri

Constantine (Algérie)

\section{من}

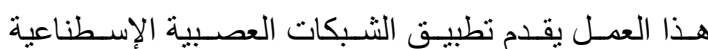

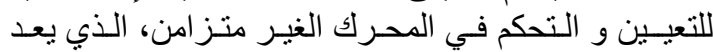

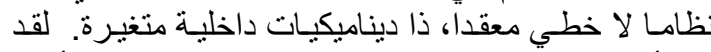

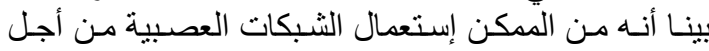

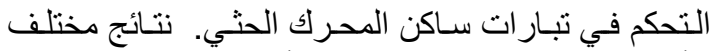

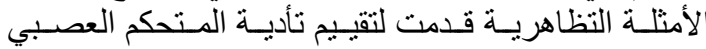

المقتر ح.

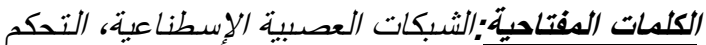

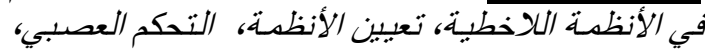
المحرك الغبير متز/من.
The interest generated by artificial neural networks in recent years years is justified by some of the fascinating properties that they justified by some of the fascinating properties that they have, such as adaptiveness, generalization, etc., which give a powerful tool to solve problems related to the control of nonlinear complex processes and to overcome the limitations of commonly used techniques [1].

Realizing an efficient command for nonlinear systems or whose dynamics are partially or totally unknown has always been an attempt to perform a less sophisticated linearization as the case of gain scheduling, adaptive control, self tuning, etc., [2], [3], [4]. Although giving results, we notice that the simplification of these systems in order to control them is not satisfactory. To alleviate the disadvantages of adaptive control, for example the sensitivity of the model, researchers have developed the notion of neurocontrol which consists of the instillation of the system's dynamic behavior to an ANN trough the back propagation learning operation $[5,6,7,8,9]$.

This scheme of intelligent control allows to decrease the chances of instability, linked to the variation of the process parameters, and thus, realize systems with intelligent self control [3].

With its size and its nonlinear nature worsened by irreducible changes in its internal characteristics in operational mode, the asynchronous machine constitutes a system of great complexity [4].

The elaboration of an advanced command for the induction motor has been the subject of multiple efforts. The solutions proposed such as the scalar control or the control by field orientation are not wholly satisfactory since they are subject to the variations of the system parameters in particular during abrupt load changes. In this In this work we propose a connectionist approach to the problem through a neuronal model of the asynchronous machine [10]. 


\section{NEUROCONTROL}

In order to produce complex systems, mainly nonlinear, capable of being autonomous in a hostile environment, researchers concentrated their attention to the development of intelligent control systems [3].

Recently, research efforts to apply ANN to the control of dynamic processes have led to the promising domain of neurocontrol, which can be seen as a connectionist branch of adaptive control theory [11]. ANN are sought to iron out the difficulties encountered with nonlinear systems or those having an unknown structure; noise rejection, fault tolerance and graceful degradation [12].

\section{1 - Neuromorphic identification}

In this context, the application of ANN in dynamic systems identification and control can be developed in a natural manner due to the adaptive nature of the networks learning process [13]. Virtually, all discrete and nonlinear systems can be represented by the Nonlinear Autoregressive Moving Average with eXogenous input model, NARMAX [14], which is described by the following nonlinear discrete differences equation:

$$
y_{p}(k+1)=f\left\lfloor y_{p}(k), \ldots, y_{p}(k-n+1) ; u(k), \ldots, u(k-m+1)\right\rfloor(1)
$$

an identification model would be to use the real inputs of the system for the training of the neural network emulator (NNE). Then, equation (1) becomes:

$$
y_{n}=N\left\lfloor y_{p}(k), \ldots, y_{p}(k-n+1) ; u(k), \ldots, u(k-m+1)\right\rfloor
$$

where $y_{n}$ is the output of the NNE.

The preceding equation describes a series-parallel model [15], which is the most appropriate model in order to generate stable adaptation rules.

\section{2 - Neuromorphic control}

The desired closed loop performance of the system is specified by a stable model $\mathrm{M}$, defined by the pairs of inputoutput $\left\{r(k), y_{M}(k)\right\}$ [8]. The controlled system attempts to follow the performance of the model, thus the control process becomes a tracking problem. In indirect adaptive control, we use a neuromodel of the system where the system's error is propagated first in the emulator then in the controller allowing the parameter adjustment of the neural network controller (NNC) [16].

\section{THE ASYNCHRONOUS MACHINE}

The induction motor is a highly nonlinear system; the study of its stability is difficult. Simulation becomes an advantageous choice for the stability and performance analysis of the control system. The application of modern control theory to the $\mathrm{AC}$ motor requires a discrete modeling of the induction motor in real time which must be fast, stable and accurate for the analysis and design of adequate digital control [17]. Such system is a perfect candidate for the use of neural network for the implementation of a robust and efficient controller. We use an ANN for the identification of the motor stator currents and present a neural network controller for these currents [10].

\section{1 - Identification}

In order to identify the stator currents of the motor, the discrete representation of the induction machine in the stator referential $d-q$ is used [18].

$$
\underline{i}^{d q}(k+1)=\Phi(k) \underline{i}^{d q}(k)+c_{v} \underline{v}^{d q}(k)
$$

with:

$$
\begin{gathered}
\Phi=\left[\begin{array}{cccc}
1-T / \tau_{s} & 0 & T \xi / \tau_{r} & T \xi \omega_{r}(k) \\
0 & 1-T / \tau_{s} & -T \xi \omega_{r}(k) & T \xi / \tau_{r} \\
T R_{22} & 0 & 1-T / \tau_{s} & -T \omega_{r}(k) \\
0 & T R_{22} & T \omega_{r}(k) & 1-T / \tau_{s}
\end{array}\right] \\
\underline{i}^{d q}=\left[i_{d s} i_{q s} \phi_{d r} \phi_{q r}\right]^{T}, \xi=L_{m} / \sigma L_{s} L_{r}, R_{22}=L_{m} R_{r} / L_{r}, \\
c_{v}=T / \sigma L_{s}, \tau_{r}=L_{r} / R_{r}, \tau_{s}=1 /\left(\frac{R_{s}}{\sigma L_{s}}+\frac{R_{r} L_{m}^{2}}{\sigma L_{s} L_{r}}\right)
\end{gathered}
$$

where $\sigma=1-L_{m}^{2} / L_{s} L_{r}$ is the leakage coefficient, $i_{d s}, i_{q s}$ are the stator currents; $\phi_{d r}, \phi_{q r}$ are the rotor fluxes; $v_{d s}, v_{q s}$ are the stator voltages and $\omega_{r}$ is the motor's speed.

This model can not be used for identification since the flux vector is not observable; i.e. can not be measured. It is possible to modify these equations in two second order equations in terms of observable quantities $i_{s}^{d q}=\left[i_{d s} i_{q s}\right]^{T}$ and $v^{d q}=\left[v_{d s} v_{q s}\right]^{T}$. The deduction of this NARMAX model is given in the appendix of reference [18]:

$$
\begin{aligned}
& \underline{i}_{s}^{d q}(k+1)=f \underline{\underline{i}}_{s}^{d q}(k), \underline{i}_{s}^{d q}(k-1), \omega_{r}(k), \\
&\left.\omega_{r}(k-1), \underline{v}^{d q}(k), \underline{v}^{d q}(k-1)\right)
\end{aligned}
$$

where $f(\cdot): \mathfrak{R}^{10} \rightarrow \mathfrak{R}^{2}$ is nonlinear.

An ANN $\aleph_{10,21,2}^{2}$ is used for the estimation of $\underline{f}(\cdot)$, where $\aleph_{10,21,2}^{2}$ stands for a network of 10 neurons in the input layer, 21 neurons in the hidden layer and 2 neurons in the output layer. The parameters of the learning algorithm can be found in [10]. Equation (4) requires the values of the stator voltages and currents in addition to the speed of the rotor. The identification model is given in figure 1 .

Gaussian samples in the input voltage current $\underline{v}^{d q}(k)$ are used to excite the electromagnetic dynamics of the induction motor in order to ensure the generality during training. The 


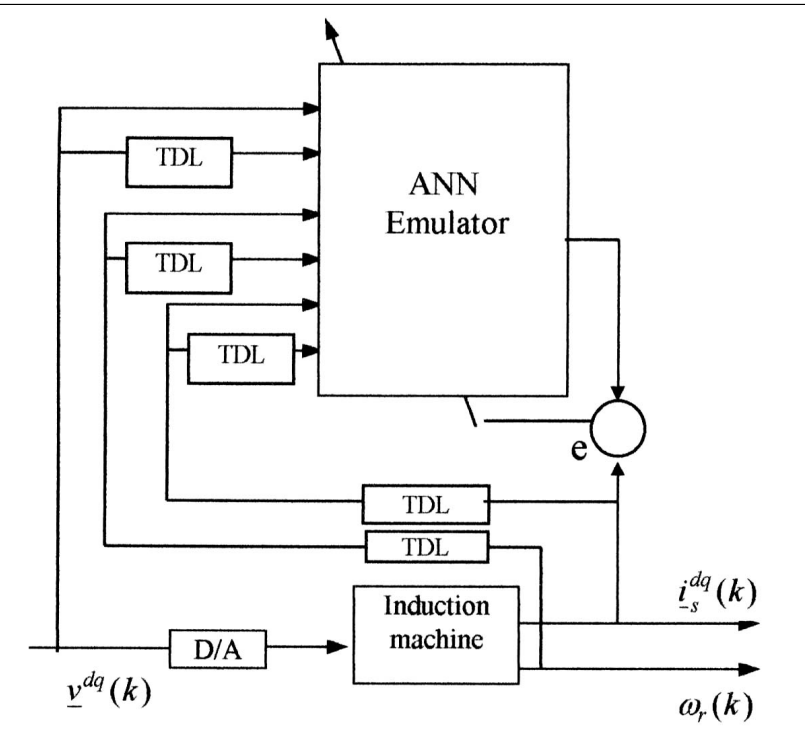

Figure 1: Current identification of the induction machine.

voltage vector $\underline{v}^{d q}(k)$, the stator current vector $\underline{i}_{-s}^{d q}(k)$ and the speed $\omega_{r}(k)$ are sampled, delayed then propagated in the ANN. We proposed an off-line training scheme of the ANN in order to reproduce existing stator current controller. The training required $526 \times 10^{3}$ presentations of the 850 training vectors. After the network convergence, the emulator is then tested with respect to the motor's output. The performances of the NNE have an acceptable accuracy. The results of the identification are obtained for the quadrature and direct currents and are presented in figures 2 and 3.
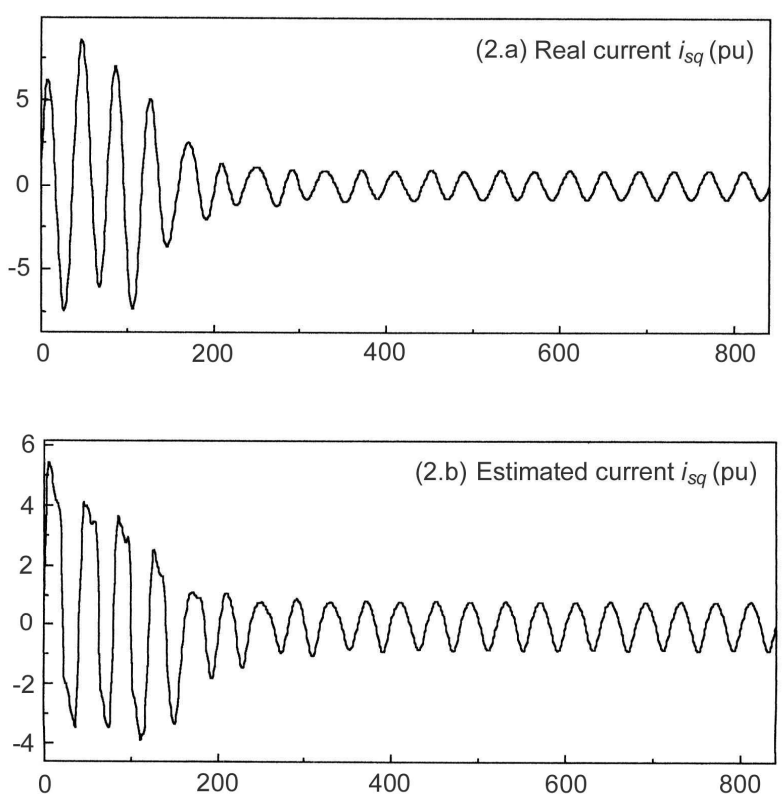

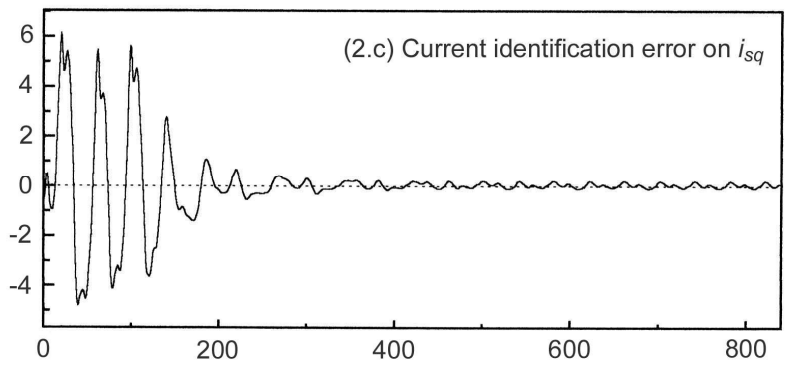

Figure 2: Quadrature current identification
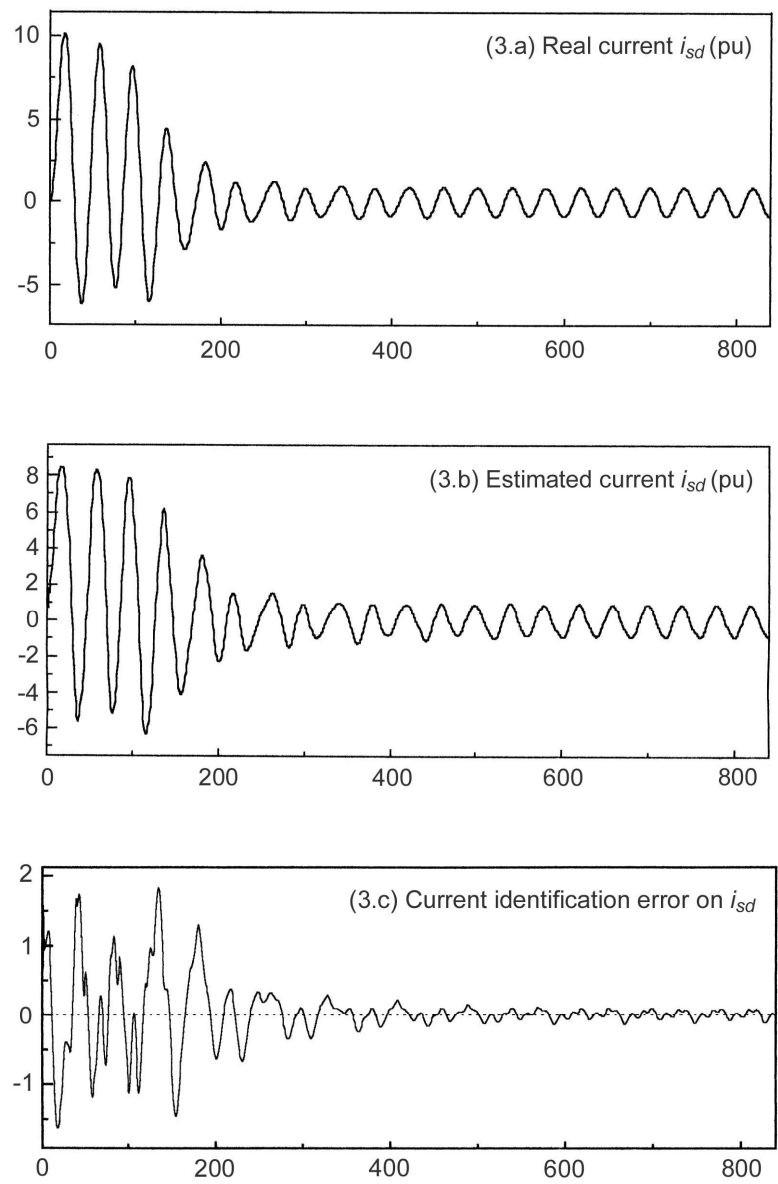

Figure 3: Direct current identification.

\section{2 - Control}

The induction motor is a nonlinear system, in addition, many parameters change with time and functioning conditions. The induction motor system is structurally a multivariable control system. The voltage and the frequency are the control inputs and the outputs can be any of the following: speed, position, torque, air-gap flux, stator current or any of their combination [7]. 
Many control methods such as the vectorial control or he direct self control attempt to reduce the complex dynamic structure to a linear structure in order to apply techniques of linear design [17]. However, the changes in the motor parameters can deteriorate the performances of the motor and lead eventually to instability, but the problem can be solved by using adaptive techniques [7].

The neuronal model obtained in section 3.1 contains all the internal dynamics of the motor and by this fact it is robust against any changes in internal parameters of the induction machine. Our controller controls the stator currents of the induction motor. Once, it is sufficiently trained, it will replace the controller, which results in high execution speed and fault tolerance [18]. The NNE of section 3 is used for training the neuronal controller as shown by figure 4 . The purpose of the control is to force $\widetilde{\tilde{i}}_{s}^{d q}$ to follow the desired stator vector $\widetilde{i}_{s}^{d q}$. Thus, the controller synthesizes the elements of the vector $\underline{v}^{d q}$ of relation (5).

$\underline{v}^{d q}=R N A\left(\underline{i}_{s}^{d q}(k), \underline{i}_{s}^{d q}(k-1), \omega_{r}(k), \omega_{r}(k-1), \underline{v}^{d q}(k), \underline{v}^{d q}(k-1)\right)$

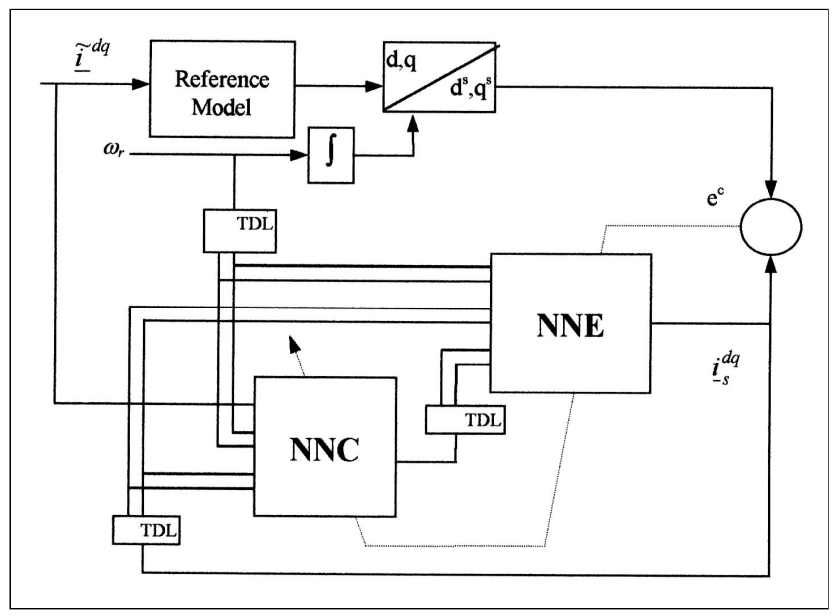

Figure 4: Neurocontroller training.

A network type $\aleph_{10,21,2}^{2}$ is trained with random samples.

The convergence of the network is obtained after $85 \times 10^{4}$ presentations of the 601 training vectors.

The NNC is applied to the asynchronous motor with no load. Then, the controller is tested with $70 \%$ change in the motor's rotor resistance. The simulation results are shown in figures 5, 6, 7 and 8 . We see that the stator currents stabilize quickly around the reference values in amplitude, phase and frequency. In addition, the test with the change in rotor resistance shows the adaptive nature of the controller. The latter reaches and remains at the reference values in less than 0.13 seconds.
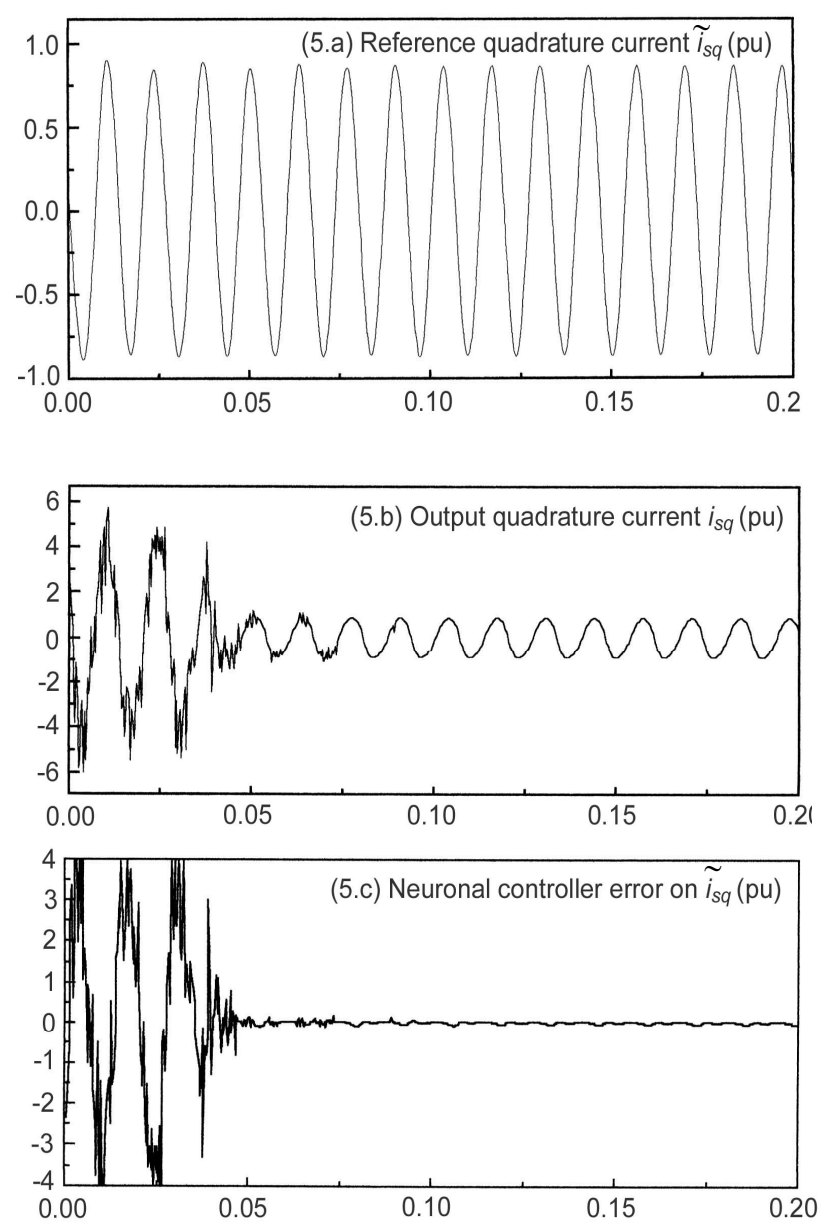

Figure 5: Quadrature current control
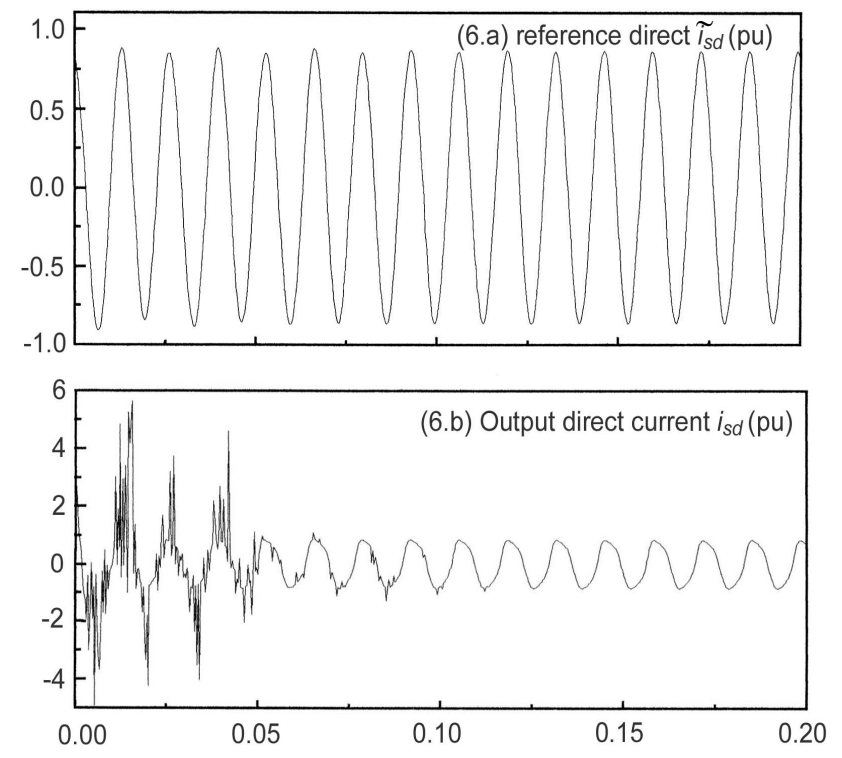


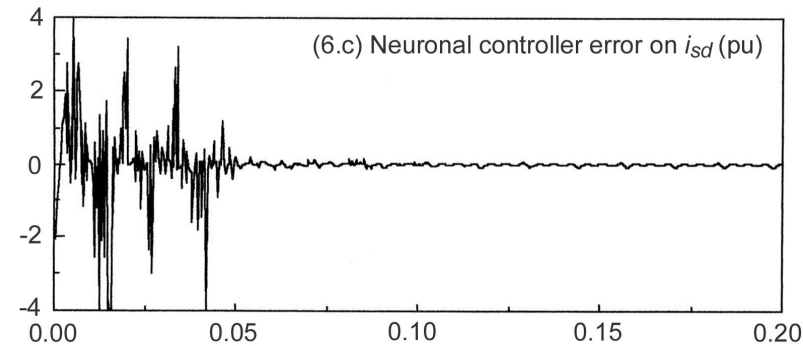

Figure 6: Direct current control.
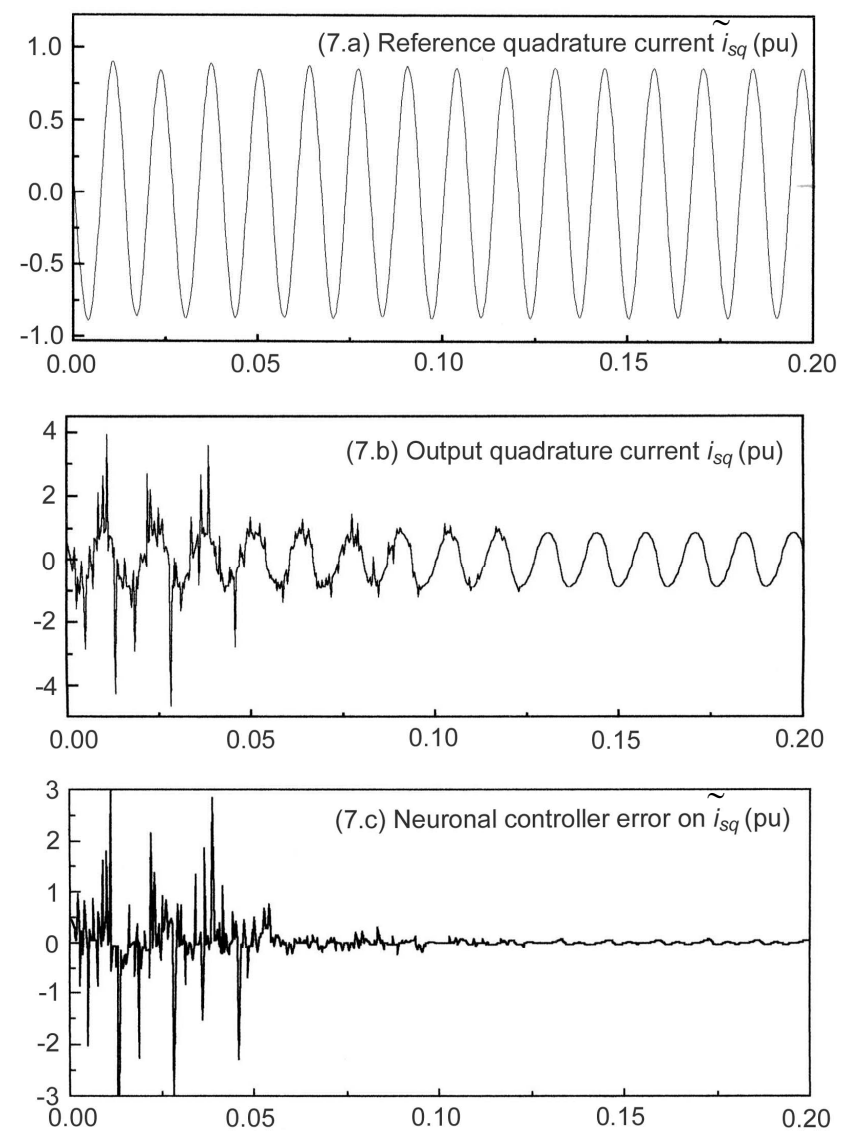

Figure 7: Quadrature current control with a charge in $\mathrm{R}_{\mathrm{r}}$.

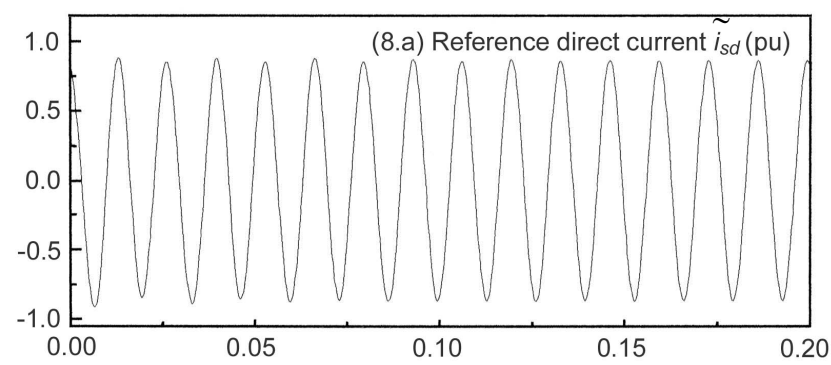

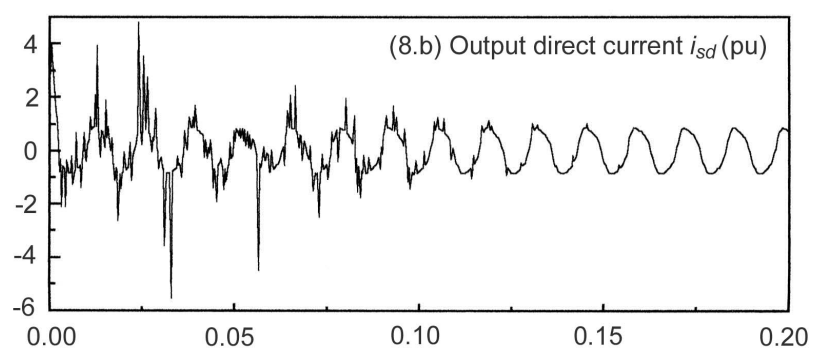

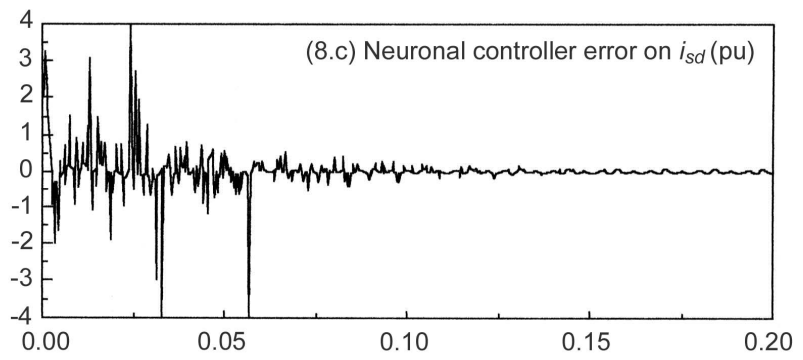

Figure 8: Direct current control with a charge in $\mathrm{R}_{\mathrm{r}}$.

\section{CONCLUSION}

According to the results obtained, it seems clear that the control with neural networks of the asynchronous machine is robust and efficient. The use of ANN for the synthesis of the control of stator currents of an asynchronous machine, in addition to its simplicity with respect to its implementation, has enabled to make the tracking of a reference model that is quick and insensitive to the motor's internal parameter changes unlike other control schemes which are robust only if the characteristics of the system are stable. Thus, neural networks represent an attractive and pertinent solution to the adaptive control. Unfortunately, the main handicap of the application of ANN is the huge training time as well as the delicate choice of the different network parameters.

\section{REFERENCES}

[1]- Y.H. Pao, S.M. Phillips and D.J. Sobajic, "Neural-net computing and the intelligent control of systems," International Journal of Control, vol. 56, $\mathrm{n}^{\circ} 2$ (1992), pp. 263-289.

[2]- K.S. Narendra and K. Parthasarathy, "Gradient methods for the optimization of dynamical systems containing neural networks," IEEE Trans. on Neural Networks, vol. 2, n² Mars (1991), pp. 252-262.

[3]- M.F. Chouikha and C. Aissi, "Design and implementation of an intelligent controller using neural networks", Proc. 32nd Midwest Symposium On Circuits And Systems, vol. 2, (1990), pp. 756-759.

[4]- B.K. Bose, Power Electronics And AC Drives. New Jersey: Prentice Hall, (1986).

[5]- B. Widrow and M. Lehr, "30 years of adaptive neural networks: Perceptron, Madaline and Backpropagation," Proc. IEEE, vol. 78, n9, Sept. (1990), pp. 1415-1441. 
[6]- R.P. Lippmann, "An introduction to computing with neural nets", IEEE, ASSP Mag., vol. 4, Apr. (1987), pp. 4-22.

[7]- T. Fukuda and T. Shibata, "Theory and applications of neural networks for industrial control systems", IEEE Trans. on Industrial Electronics, vol.39, nº, Dec. (1992), pp. 472-489.

[8]- K.J. Hunt, D. Sbarbaro, R. Zbikowski and P.J. Gawthrop, "Neural networks for control systems- a survey", Automatica, vol.38, n6 (1992), pp. 1083-1112.

[9]- D.H. Nguyen and B. Widrow, "Neural networks for selflearning control systems," IEEE Control Systems Magazine, vol.10, Iss: 3, Apr. (1990), pp. 18-23.

[10]-A. Zergaoui, Identification et Contrôle d'une Machine Asynchrone par les Réseaux de Neurones. Thèse de Magister, Université Mentouri, Constantine, (1997).

[11]- J. Tanomaru and S. Omatu, "Process control by on-line trained neural controllers", IEEE Trans. on Industral Eectronics, vol. 39, nº, Dec. (1992), pp. 511-521.

[12]-R.M. Sanner and D.L. Akin, "Neuromorphic pitch attitude regulation of an underwater telerobot, "IEEE Control
Systems Magazine, Apr. (1990), pp. 62-67.

[13]- V. Etxebarria, "Adaptive control of discrete systems using neural networks", IEE Proc. Control Theory Appl., vol. 141, n4, July (1994), pp. 209-215.

[14]-S. Weerasooriya and M.A. El-Sharkawi, "Identification and control of a DC motor using back-propagation neural networks," IEEE Transactions on Energy Conversion, vol.6, n4, Dec. (1991), pp. 663-669.

[15]-K.S. Narendra and K. Parthasarathy, "Identification and control of dynamical systems using neural networks", IEEE Transactions on Neural Networks, vol. 1, $\mathrm{n}^{\circ} 1$ (Mar. 1990), pp. 04-26.

[16]- A. Carrière and Y. Hamam, "Heat pump emulation using neural networks", IEEE International Conference on Systems Engineering, (1992), pp. 503-506.

[17]- N.S. Gehlot and P.J. Alsina, "A discrete model of induction motors for real-time control applications", IEEE Trans. on Industrial Electronics, vol. 40,n³, (Jun. 1993), pp. 317-322.

[18]-M.T. Wishart and R.G. Harley, "Identification and control of induction machines using artificial neural networks", IEEE Trans. on Industry Applications, vol. 31, n³, May/Jun. (1995), pp. 612-619. 